\title{
Protection and Inheritance of the Original Ecological Oroqen Music Heritage
}

\author{
Zuping Xu \\ School of Music \\ Heihe University \\ Heihe, China 164300
}

\author{
Xiaofei Sun \\ School of Music \\ Heihe University \\ Heihe, China 164300
}

\begin{abstract}
The original ecological music is an important treasure of our country. This paper first analyzes the original ecological music, discusses the original ecological Oroqen music and its situation as well as the artistic characteristics of the original ecological Oroqen music from the structure function and the form of melody. The original ecological Oroqen music has a positive significance on the society in the aesthetics, nationality, inheritance and education. The Oroqen music is original ecological, but the current situation of its existence and development is not optimistic. The original ecological musical form of the minorities is in urgent need of protection.
\end{abstract}

Keywords - the original ecological Oroqen music; heritage; protection

\section{INTRODUCTION}

With the development of history and culture in our country, the ethnic music culture accumulates and develops continuously in the long history, leaving a breathtaking artistic trace. Our country has entered the new era with joint development of diversified cultures. Different styles of music flourishes. The original ecological ethnic music and the modern popular music influence each other and show different development tendencies. As an important part of the ethnic music in our country, the original ecological Oroqen music is under the impact of western musical culture and pop music culture in society. When the time factor integrates in it, problems like culture elimination appear inevitably. Although it conforms to the objective law of the music culture development, it is still a great loss for the national intangible cultural heritage of our country. Therefore, it is imperative to protect and rescue the original ecological Oroqen music culture. The main purpose of this paper is to provide theoretical basis for the protection of it.

\section{CURRENT SituAtion OF THE ORIGINAL ECOLOGICAL OROQEN MUSIC}

Unique ethnic cultures are bred by the Oroqen people living in the mountain forest from generation to generation. The distinct national character and music artistic style and connotation of the Oroqen people correspond to the culture. The original ecological Oroqen music has relationship with the mountain forest and the nature. The lifestyle of people decides

Fund project: 2016 Heilongjiang Province Philosophy and Social Science Research Planning Project Funding (support the co-building project), Project title: Research on the Protection and Inheritance of the Original Ecological Music Heritage in Oroqen, Project number: 16YSE06. the concrete forms of the ethnic music: The awe for the nature and the mountain forest derives the Shaman Divine Song. The Ludi used for attracting prey finally becomes the Oroqen ethnic instrument. The traditional Oroqen music shows the thoughts and wisdom of the Oroqen people through inheritance and development. The ethnic original ecological music is one of the symbols of traditional culture of Chinese characteristics, with strong cultural vitality and embodying the essence of culture and the national spirit. Different from other nationalities, the Oroqen people express their emotions through singing and dancing joyously. The Oroqen music has the regional features of Xinganling, but because the number of Oroqen people is small, the spread scope of the original ecological music is very narrow and the music is disappearing. It is an arduous and complicated task for scholars to research on how to rescue and protect it.

\section{Protective MeAsures of ThE ORIGINAL ECOLOGICAL OROQEN MUSIC}

The original ecological Oroqen music is fragile and it is difficult to deal with many problems in the inheritance and development. Countermeasures have been proposed according to the current situation, predicament and problems to intensify the protection: The protection of the Oroqen music is not only the responsibility of the Oroqen ethnic group but also the task in researching on the regional culture of Heilongjiang.

\section{A. Understand the Lifestyle of the Oroqen People}

The Oroqen ethnic group has unique lifestyle. They live on the horseback. To know their music, firstly, it is necessary to understand their lifestyle, which is the source of music art, and research on their living environment in detail; secondly, research on their culture and art roundly under the situation that there is language instead of words among the Oroqen people. From the perspective of the longitudinal historical perspective of human development, the inheritance and development is not only to continue the blood relationship but also to spread the social civilization. The inheritance and protection of ethnic culture needs creators and carriers, namely the masses. Therefore, the inheritance and protection of the Oroqen music culture needs to combine with the cultural image shaping of the Oroqen ethnic people and strengthen people's sense of identity and pride of the ethnic culture, deeply excavating the inner creative power of ethnic culture 
and letting the inheritance become the common will of the masses instead of only the responsibility of the government sector and professionals, in order to promote people's spiritual living level and ensure the physical and mental health of them.

\section{B. Pay Attention to the Folk Inheritance Form}

As we all know, there is only language instead of words among the Oroqen people. The folk songs are inherited through people's lips and ears. At present, most young Oroqen people marry with the people of other ethnic groups and the lifestyle has changed a lot. Besides, most of the old people who can sing the Oroqen songs have passed away. Therefore, it is necessary to collect and tease the existing music pieces roundly. It is a complicated and difficult task because of the frequent contacts between the Oroqen people and the Han people, the changes of the modernized production and life and the involvement of some creation techniques and elements of the Han music. The most original traditional music is disappearing. Therefore, the original ecological Oroqen music includes three parts: the first is the original music passed from mouth to mouth; the second is the musical form adapted and recorded with the elements of other nationalities; the third is the musical form learned by the Oroqen people. It needs to distinguish and mark the Oroqen musical forms.

\section{Arouse the Consciousness of the Oroqen Ethnic Group}

The dwelling state of the Oroqen people is that some ethnic groups live together over vast areas while some live in individual concentrated communities in small areas. Although there are ethnic townships and villages, the Oroqen people live with the ethnic Han in the strict sense. The forms of culture and art of ethnic minorities are more or less influenced by the Han culture. The cultural fusion should be carried out among the Oroqen people. The inheritance of the Oroqen music is mainly conducted between communities which are the gathering place of the Oroqen people. Nowadays, the community life of the Oroqen people is colorful. In the daily life, some people dance with the music. It is organized by the community residents spontaneously according to their hobbies and interests to build the body, as well as a popular expression form of the Oroqen dance. It is helpful to protect and inherit the ethnic culture.

\section{Strengthen the Practical Inheritance of the Original Ecological Music Culture}

Because of losing the living environment, the original ecological music culture is increasingly exhausted. We have to inherit and protect it through ethnic festivals, establishing the culture brands and showing the folk customs in the tourism. For example, the Gu Lun Mu Da festival has attracted a great number of Chinese and foreign tourists in recent years and the extensive attention of all sectors of society. It will play a positive and important role in spreading the traditional music through combining the traditional festivals with the traditional culture and art while promoting the development of the traditional Oroqen culture and economy. The government plans and arranges in detail to let more people participate in the activity. The folk activities help people to understand the most traditional Oroqen music and let more people become interested in the Oroqen music culture. Moreover, in developing the tourism resources, the original traditional Oroqen music can be regarded as an attractive point through popularizing and promoting the traditional festivals. Meanwhile, the original ecological Oroqen music can be inherited and protected in promoting the development of tourist economy. Currently, the Gu Lun Mu Da festival is the main stage to show people the original ecological Oroqen music. With the continuous development of society, the coexistence and common prosperity relationship is built between the festival and the original ecological Oroqen music. It is an important opportunity to inherit and further develop the original ecological Oroqen music culture through improving the popularity and influence of the Oroqen ethnic festivals like the Gu Lun Mu Da festival.

\section{E. Carry forward the Original Ecological Music in the Reference}

Firstly, it needs to ensure the inheritance of the original ecological music culture in the local areas and exert the research and promotion function of music workers to inherit the music culture. According to the realistic condition, as the precious intangible cultural heritage, the original ecological Oroqen music culture is grasped by the Oroqen folk artists. We should promote the longitudinal family inheritance and the horizontal spread in small areas. The elders should be encouraged to lead the inheritance of culture through the cross spread between father and son as well as among the inner ethnic groups, stimulate the passion of younger generation for the local ethnic music culture as well as guide them to understand, learn and grasp it, so as to ensure the inheritance to some extent. At the meantime, the music workers of the Oroqen ethnic group are familiar with the music culture and can research on the music culture objectively. More import

\section{F. Pay Attention to the Cultural Heritage and Provide a Strong Support}

According to the development status of ethnic culture in our country, undoubtedly, the original ecological Oroqen music culture has become one of the important contents of the intangible cultural heritage. Mosukun and so on have been included in the nonmaterial cultural heritage list of our country, showing the original ecological Oroqen music culture has been endowed with new properties in public benefit and business in the new era. Therefore, the government sectors need to build and improve the scientific and systematic mechanism and provide an effective system guarantee to support the inheritance and further development of the original ecological Oroqen music culture. Props and clothes should be provided for performers to ensure the implementation of activities performed by the Oroqen folk arts groups and achieve the purpose of mass communication through effective media and ways. The Oroqen music and culture can be popularized and the economic value of the traditional music can be emphasized through the continuous spread of information and its influence on the audiences. For example, the tourism wave can be used to organize colorful folk activities in the legal holidays and excavate the folk cultural values contained in it and realize the development of cultural protection and tourist economy, so as to popularize and protect the music. The traditional inheritance 
form of the original ecological Oroqen music restricts its inheritance. Therefore, specialized music talents are required to record and systematically tease the songs and dances of folk artists of the older generation and enrich the record of folk music. Therefore, we needs to extensively gather talents interested in learning and researching the original ecological Oroqen music and train them scientifically and systematically, encourage the young people to learn and inherit the traditional music. It is necessary to bring the traditional music into the teaching system, provide courses to teach the original ecological music and train specialized music talents as well as pay more attention to the original ecological Oroqen music in school education. We need to inherit and protect it because it will never be copied once disappearing. We don't save the Oroqen culture in the museums but let it show the original state and exist in people's real life. All of us should make concerted efforts to inherit and develop the ethnic culture smoothly. The inheritance and development of the original ecological Oroqen music culture can be realized through the joint collaboration and support.

\section{CONCLUSION}

All in all, the protection of the original ecological Oroqen music heritage doesn't means laying aside and neglecting it but needs to find new inspiration in it, inherit and carry forward the music tradition, letting it get sublimation in reality.

\section{REFERENCES}

[1] Wang Jiesi. Analysis on the Expression Form of the Oroqen Folk Song-Analysis on the Expression Form of the Oroqen Folk Song with "Zan Da Ren" as an Example [J], Musical Creation, 2016 (4).

[2] Yu Ye, Wang Rui. Reform and Practice of the Heilongjiang Minority Traditional Music Course-The Application of the Remaining Sound of the Original Music Culture to the Classroom Construction [J], Artistic Research, 2009(4): 104-105.

[3] Du Juan. Research on the Outlook on Environmental Ethics in the Original Ecological Oroqen Culture [D], Hunan Normal University, 2011. 